\title{
Predicting response to incretin-based therapy
}

This article was published in the following Dove Press journal:

Research and Reports in Endocrine Disorders

6 April 2011

Number of times this article has been viewed

\author{
Sanjay Kalra' \\ Bharti Kalra ${ }^{2}$ \\ Rakesh Sahay ${ }^{3}$ \\ Navneet Agrawal ${ }^{4}$ \\ 'Department of Endocrinology, \\ ${ }^{2}$ Department of Diabetology, Bharti \\ Hospital, Karnal, India; ${ }^{3}$ Department \\ of Endocrinology, Osmania \\ Medical College, Hyderabad, India; \\ ${ }^{4}$ Department of Medicine, GR Medical \\ College, Gwalior, India
}

\begin{abstract}
There are two important incretin hormones, glucose-dependent insulin tropic polypeptide (GIP) and glucagon-like peptide-1 (GLP-1). The biological activities of GLP-1 include stimulation of glucose-dependent insulin secretion and insulin biosynthesis, inhibition of glucagon secretion and gastric emptying, and inhibition of food intake. GLP-1 appears to have a number of additional effects in the gastrointestinal tract and central nervous system. Incretin based therapy includes GLP-1 receptor agonists like human GLP-1 analogs (liraglutide) and exendin-4 based molecules (exenatide), as well as DPP-4 inhibitors like sitagliptin, vildagliptin and saxagliptin. Most of the published studies showed a significant reduction in $\mathrm{HbA}_{1 \mathrm{c}}$ using these drugs. A critical analysis of reported data shows that the response rate in terms of target achievers of these drugs is average. One of the first actions identified for GLP-1 was the glucose-dependent stimulation of insulin secretion from islet cell lines. Following the detection of GLP-1 receptors on islet beta cells, a large body of evidence has accumulated illustrating that GLP-1 exerts multiple actions on various signaling pathways and gene products in the $\beta$ cell. GLP-1 controls glucose homeostasis through well-defined actions on the islet $\beta$ cell via stimulation of insulin secretion and preservation and expansion of $\beta$ cell mass. In summary, there are several factors determining the response rate to incretin therapy. Currently minimal clinical data is available to make a conclusion. Key factors appear to be duration of diabetes, obesity, presence of autonomic neuropathy, resting energy expenditure, plasma glucagon levels and plasma free fatty acid levels. More clinical evidence is required to identify the factors affecting response rate to incretin therapy.
\end{abstract}

Keywords: liraglutide, exenatide, type 2 diabetes, insulin secretion, clinical response

\section{Introduction}

The term "incretin effect" is used to describe the fact that an oral glucose load produces a greater insulin response than an intravenous glucose infusion which gives similar glycemic response, or causes an equivalent rise in blood glucose as the oral glucose load. ${ }^{1-4}$ This difference is due to gastrointestinal hormones that are released during nutrient ingestion and stimulate insulin secretion in excess of that elicited by intravenous glucose. This stimulation is due to the effect of the so-called "incretin hormones" or "incretins". ${ }^{1}$ The incretin effect is responsible for up to $60 \%$ of insulin secretion after glucose ingestion in normal subjects. ${ }^{4}$ The incretin effect is impaired in most patients with type 2 diabetes. However it is still not clear whether it is a cause or a consequence of hyperglycemia.

There are two important incretin hormones, glucose-dependent insulinotropic polypeptide (GIP) and glucagon-like peptide-1 (GLP-1). GIP, previously known as 
gastric inhibitory polypeptide, is secreted from K-cells of the upper small intestine and GLP-1 is secreted from the L-cells of the lower small intestinal mucosa. Their action as incretins has been well documented in both animal (eg, with the use of specific receptor antagonists ${ }^{5,6}$ or targeted receptor disruptors ${ }^{7}$ ) and human studies. ${ }^{8-10}$ Both the incretins enhance glucose induced insulin secretion from pancreatic $\beta$-cells. However their action on glucagon secretion is conflicting, GLP-1 being an inhibitor of glucagon secretion while GIP may have no effect or even increase glucagon secretion. In addition the effect of GLP-1 remains intact in type 2 diabetes though its meal-time secretion is reduced while the secretion of GIP remains either normal or is sometimes elevated in type 2 diabetes. This makes GLP-1 an attractive therapeutic target in type 2 diabetes.

The biological activities of GLP-1 include stimulation of glucose-dependent insulin secretion and insulin biosynthesis, inhibition of glucagon secretion and gastric emptying, and inhibition of food intake. GLP-1 appears to have a number of additional effects in the gastrointestinal tract and central nervous system. ${ }^{11}$ The finding that GLP-1 lowers blood glucose in patients with diabetes, taken together with suggestions that GLP-1 may restore $\beta$-cell sensitivity to exogenous secretagogues, suggests that augmenting GLP-1 signaling is a useful strategy for treatment of diabetic patients. There are a number of different GLP-1 targets or loci that may be exploited to enhance GLP-1 action in diabetic subjects. Incretin-based therapy is a newer class of treatment for type 2 diabetes. This includes GLP-1 receptor agonists such as human GLP-1 analogs (liraglutide) and exendin-4 based molecules (exenatide), as well as DPP-4 inhibitors such as sitagliptin, vildagliptin, and saxagliptin. ${ }^{12}$ Many other drugs in this class are in various stages of development.

This review focuses mainly on the incretin mimetics such as liraglutide and exenatide.

While extensive research has been done on the efficacy and safety of these incretin-based therapies, little clinical work has been done to understand the determinants of response to these drugs. Theoretically, response to these promising new drugs depends not just on $\beta$-cell function but also on other factors such as degree of impairment of incretin effect. In the case of DPP-4 inhibitors the response also depends on amount of endogenous GLP-1 secretion. Though incretin-based therapy is recommended for early in the course of type 2 diabetes no definite consensus has emerged regarding the "type of patient" who does or does not respond to incretin-based therapy. Liraglutide and exenatide are compared provided in Table 1.
Table I Comparison of liraglutide and exenatide

\begin{tabular}{ll}
\hline Liraglutide & Exenatide \\
\hline Once daily injection & Twice daily injection \\
Peakless & Rise to a peak and fall \\
Weight loss & Significant weight loss \\
Good effect on $\mathrm{HbA}$ Ic and FPG & Good effect on $\mathrm{HbA}_{\mathrm{Ic}}$ \\
No antibodies to analogs & Antibodies to exenatide \\
Negligible injection site reaction & Injection site reactions occur \\
\hline
\end{tabular}

Abbreviations: $\mathrm{FPG}$, fasting plasma glucose; $\mathrm{HbA}_{1 \mathrm{c}}$, glycated hemoglobin.

\section{Glycated hemoglobin lowering with incretin-based therapy}

Most of the published studies showed a significant reduction in glycated hemoglobin $\left(\mathrm{HbA}_{1 \mathrm{c}}\right)$ using these drugs. Liraglutide treatment led to impressive $\mathrm{HbA}_{1 \mathrm{c}}$ reduction of up to $1.6 \%$ as monotherapy. ${ }^{13}$ Exenatide reduced a baseline $\mathrm{HbA}_{1 \mathrm{c}}$ of about $7.8 \%$ by $0.7 \%$ to $0.9 \%$ when used as monotherapy, ${ }^{13,14}$ while a once-weekly preparation of the same drug show better results. Exenatide, studied as monotherapy in patients with type 2 diabetes naive to antidiabetic agents, has shown effective glycemic control. $\mathrm{HbA}_{1 \mathrm{c}}$ reductions (\%) from baseline were significantly greater with exenatide 5 and $10 \mu \mathrm{g}$ than [placebo] $(-0.7[0.1]$ and -0.9 [0.1] vs -0.2 [0.1]; $P=0.003$ and $P<0.001$, respectively), as were fasting serum glucose $(\mathrm{FSG})$ reductions $(\mathrm{mg} / \mathrm{dL})$ $(-17.5$ [4.0] and -18.7 [4.0] vs -5.2 [4.0]; $P=0.029$ and $P=0.016$, respectively). Changes in daily mean postprandial glucose excursions $(\mathrm{mg} / \mathrm{dL})$ from baseline to end point were significantly greater with exenatide 5 and $10 \mu \mathrm{g}$ than placebo $(-21.3$ [2.7] and -24.7 [2.7] vs -8.3 [2.5]; both, $P<0.001)$. With exenatide 5 and $10 \mu \mathrm{g}, 31 \%$ and $35 \%$ of patients achieved $\mathrm{HbA}_{1 \mathrm{c}} \leq 6.5 \%$ at end point vs $19 \%$ with placebo ( $P=$ NS and $P=0.026$, respectively), while $48 \%$ and $46 \%$ vs $29 \%$ achieved $\mathrm{HbA}_{1 \mathrm{c}} \leq 7.0 \%(P=0.024$ and $P=0.036$, respectively). ${ }^{13}$

Exenatide once weekly, which is under review by the US Food and Drug Administration, elicits sustained glycemic control $\left(-1.8 \%\right.$ reduction in $\left.\mathrm{HbA}_{1 \mathrm{c}}\right)$, along with a reduction in bodyweight $(-3.6 \mathrm{~kg})$, and an improvement in cardiovascular risk factors. ${ }^{14}$

Various DPP-4 inhibitors, such as vildagliptin, saxagliptin, and sitagliptin, also improve glycemic control, but to a lesser extent. ${ }^{15}$ Leraglutide $(1.8 \mathrm{mg})$ has been compared headto-head against exenatide (10 $\mu \mathrm{g} /$ day) in the LEAD 6 study, a 26-week open-label, parallel-group, multinational study. The primary outcome was change in $\mathrm{HbA}_{1 \mathrm{c}}$. Liraglutide reduced mean $\mathrm{HbA}_{1 \mathrm{c}}$ significantly more than did exenatide $(-1.12 \%$ vs $-0.79 \%$; estimated treatment difference -0.33 ; $P<0.0001)$ and more patients achieved a $\mathrm{HbA}_{1 \mathrm{c}}$ value of 
less than $7 \%$ (54\% vs $43 \%$, respectively; odds ratio 2.02 ; $P=0.0015)$. Liraglutide reduced mean fasting plasma glucose (FPG) more than did exenatide $(-29 \mathrm{mg} / \mathrm{dL}$ vs $-11 \mathrm{mg} / \mathrm{dL}$; estimated treatment difference $-18.2 \mathrm{mg} / \mathrm{dL} ; P<0.0001)$ but postprandial glucose control was less effective after breakfast and dinner. Both drugs promoted similar weight loss (liraglutide $-3.24 \mathrm{~kg}$ vs exenatide $-2.87 \mathrm{~kg}$ ). Both drugs were well tolerated, but nausea was less persistent (estimated treatment rate ratio $0.448, P<0.0001$ ) and minor hypoglycemia was less frequent with liraglutide than with exenatide (1.93 vs 2.60 events per patient per year; rate ratio $0.55 ; P=0.0131 ; 25.5 \%$ vs $33.6 \%$ had minor hypoglycemia). Two patients in the exenatide group had a major hypoglycemic episode. After 26 weeks patients on twice-daily exenatide were shifted to once-daily liraglutide in an open label extension for next 14 weeks. Switching from exenatide to liraglutide further and significantly reduced $\mathrm{HbA}_{1 \mathrm{c}}(0.32 \%), \mathrm{FPG}(16.2 \mathrm{mg} / \mathrm{dL})$, bodyweight $(0.9 \mathrm{~kg})$, and SBP (3.8 mmHg) with minimal hypoglycemia (1.30 episodes/ patient-year) or nausea (3.2\%). Among patients continuing on liraglutide, further significant decreases in bodyweight $(0.4 \mathrm{~kg})$ and SBP $(2.2 \mathrm{mmHg})$ occurred with 0.74 episodes/ patient-year of minor hypoglycemia and $1.5 \%$ experiencing nausea. In summary, liraglutide once daily provides significantly greater improvements in glycemic control than does exenatide twice daily, and is better tolerated. ${ }^{16}$

Liraglutide $(1.2 \mathrm{mg} /$ day and $1.8 \mathrm{mg} /$ day $)$ has also been compared against the DPP-4 inhibitor sitagliptin $(100 \mathrm{mg} /$ day $)$ in a head-to-head parallel-group, open-label trial as adjunct treatments to metformin. Greater lowering of mean $\mathrm{HbA}_{1 \mathrm{c}}$ was achieved with $1.8 \mathrm{mg}$ liraglutide $(-1.50 \%)$ and $1.2 \mathrm{mg}$ liraglutide $(-1.24 \%)$ than with sitagliptin $(-0.90 \%)$. Estimated mean treatment differences for liraglutide vs sitagliptin were $-0.60 \%(P<0.0001)$ for $1.8 \mathrm{mg}$ and $-0.34 \%(P<0.0001)$ for $1.2 \mathrm{mg}$ liraglutide. Nausea was more common with liraglutide (59 [27\%] patients on $1.8 \mathrm{mg}$; $46[21 \%]$ on $1.2 \mathrm{mg}$ ) than with sitagliptin (10 [5\%]). Minor hypoglycemia was recorded in about $5 \%$ of participants in each treatment group. In conclusion liraglutide was superior to sitagliptin for reduction of $\mathrm{HbA}_{1 \mathrm{c}}$, and was well tolerated with minimum risk of hypoglycemia. ${ }^{17}$

\section{Response rate to incretin-based monotherapy}

Less emphasis has been put on the percentage of individuals who actually respond to incretin therapy. A critical analysis of reported data shows that the response rate to these drugs, in terms of target achievers, is average.
The number of patients reaching the American Diabetes Association target of an $\mathrm{HbA}_{1 \mathrm{c}}$ of $<7 \%$ are considered as target achievers. The percentage of target achievers is one of the measures of response rate (RR) and this RR to liraglutide was $43 \%$ and $51 \%$ with $1.2 \mathrm{mg}$ and $1.8 \mathrm{mg}$ of daily dose, respectively, when given as monotherapy (LEAD-3). This RR was significantly higher $(P=0.0007, P<0.0001)$ than the $28 \%$ RR with glimepiride $8 \mathrm{mg} .{ }^{18}$ The liraglutide monotherapy RR is almost similar to that of exenatide (up to $48 \%$ ) and the gliptins (up to $69 \%$ ). Though many treated subjects reached the target, a significant number of patients remained uncontrolled. This could be due to the short duration of trial. Similar response rates are also seen in treat-to-target trials with insulin therapy. However response to incretin-based therapy is not uniform in real life practice. Significant numbers of patients fail to respond to exenatide and gliptins in our clinical practice (upublished data). Similar observations are also shared by our colleagues. The objective of this review is to look at factors, apart from duration of diabetes and $\beta$-cell function, that could be affecting response to incretin therapy.

\section{Determinants of response to incretin therapy}

Bearing in mind the average response rate, and the aboveaverage cost of this class of drugs, it becomes imperative to find out clinical or easily measurable biochemical features which can predict a positive response to incretin-based therapy. Available clinical data on such predictors are minimal. No association has been noted with age, gender, or baseline body mass index, and $\mathrm{HbA}_{1 \mathrm{c}}$ response to exenatide, liraglutide, sitagliptin, or vildagliptin. The therapies have been positioned for recent-onset diabetes at one end of the spectrum, and for elderly diabetics at the other. Liraglutide, in fact, has been shown to be effective when prescribed at virtually every step of the natural history of diabetes. ${ }^{12}$

As no clinical data are available, one has to depend on preclinical data to frame a hypothesis upon which to base one's clinical decisions on selecting patients for incretin-based therapy.

\section{$\beta$-cell function and incretin effect}

One of the initial properties identified for liraglutide was the glucose-dependent stimulation of insulin secretion from islets in rodents, humans, or from islet cell lines..$^{19} \mathrm{After}$ to the detection of GLP-1 receptors on islet $\beta$-cells, evidence has accumulated demonstrating that liraglutide exerts multiple actions on various signaling pathways and protein synthesis in the $\beta$-cell. 
Even though original studies proved that liraglutide activates cyclic adenosine monophosphate (cAMP) in islet $\beta$-cells, succeeding trials also established GLP-1-dependent variations in intracellular calcium. ${ }^{20}$ GLP-1R-/- $\beta$-cells exhibit abnormalities in levels of glucose-stimulated cAMP and in glucose-stimulated calcium oscillations. GLP-1, and to a lesser extent glucagon, stimulate coordinate oscillations in both intracellular calcium and cAMP in $\beta$-cells, which are potentiated in the presence of elevated glucose concentrations. CAMP oscillations appear sufficient for stimulation of insulin exocytosis, whereas more sustained elevations in cAMP are required for nuclear protein kinase (PKA) translocation leading to cAMP response element binding activation, and likely cell proliferation and survival. These findings illustrate a molecular mechanism differentiating transient vs sustained GLP-1 receptor activation leading to differential downstream signal transduction events. ${ }^{21}$

Furthermore, evidence for constitutive signaling of GLP-1 receptors in islet $\beta$-cells is found in studies of islet cells incubated with the antagonist exendin or in studies of immortalized GLP-1R-/- $\beta$-TC cells. ${ }^{22}$ More recent experiments have indicated that although GLP-1 increases islet cAMP, many of the subsequent changes that occur in the $\beta$-cell are PKA-independent. The growth effects of GLP-1 on islet cells may be mediated by the PI-3 kinase pathway. ${ }^{23}$ The exact downstream signaling pathways utilized by liraglutide in the islet $\beta$-cell remains a subject of intense interest.

Several studies have implicated a role for cAMP-regulated guanine nucleotide exchange factors as downstream mediators of liraglutide signaling in $\beta$-cells. Intriguingly, experiments in INS-1 cells show that although PKA inhibitors such as H-89 may not abrogate many components of GLP-1 receptor signaling, the cAMP antagonist 8-Br-Rp-cAMPS functions as a more complete inhibitor, likely as a result of its actions on cAMP-GEF II. Indeed, a dominant negative cAMP-GEF II cDNA blocked intracellular $\beta$-cell calcium release mediated by forskolin and antisense oligonucleotides against cAMP-GEF II further reduced insulin secretion in the presence of H-89. ${ }^{24}$ Hence the cAMP-GEF II signaling complex, interacting with Rim2, likely accounts for a substantial proportion of PKA-independent GLP-1 receptor signaling in $\beta$ cells.

The liraglutide-stimulated increase in insulin mRNA is likely mediated in part via cAMP. It is well known that cAMP increases both insulin gene transcription and stabilizes insulin mRNA. Similarly, liraglutide increases insulin mRNA in part via enhanced mRNA stability, and possibly through increased insulin gene transcription. ${ }^{25,26}$ The effect of liraglutide on the insulin gene promoter appears to be mediated by two distinct cis-acting sequences, both in a PKA-dependent and PKA-independent manner, depending on the experimental model used. ${ }^{27}$ Inhibition of p38 mitogen-activated protein kinase (p38 MAPK) using a chemical inhibitor SB 203580 resulted in a marked increase in insulin promoter activity in response to liraglutide stimulation, implying the existence of a functional interaction between GLP-1 and MAPK signaling pathways. ${ }^{28}$ Pugazhenthi and colleagues examined the effects of exendin-4 treatment of human islets from non-diabetic donors.

Exendin-4 modestly suppressed the expression of chemokines (CXCL9, CXCL10, and CXCL11) following induction of an inflammatory response by treatment of islets with IFN- $\gamma$. Small reductions in STAT-1 were also observed and these anti-inflammatory effects were mimicked by forskolin and the effects of exendin-4 were potentiated by phosphodiesterase inhibitors. Similar findings were obtained in Min-6 insulinoma cells in a PKA-independent manner independent of $\mathrm{H}-89 .{ }^{29}$

One of the first clues to the pleiotropic beneficial effects of GLP-1 on islet $\beta$-cells was the finding that GLP- 1 enhanced the number of glucose-responsive islet cells in vitro. ${ }^{30}$ This effect of GLP-1 appears to extend to diabetic islets. ${ }^{31}$ Does GLP-1 enhance the processing of proinsulin to insulin in normal subjects or patients with impaired glucose tolerance (IGT) or diabetes? This question is being studied in multiple clinical trials. Human subjects with IGT infused with GLP-1 exhibit a decreased circulating ratio of proinsulin to insulin. Nevertheless, the rapid kinetics of these changes does not permit any definite conclusions about GLP-1-regulated proinsulin processing vs regulation of secretion or clearance, for example. ${ }^{32}$

\section{Duration of diabetes and incretin response}

During the evolution of type 2 diabetes, insulin resistance stabilizes early, becoming constant; initially pancreatic $\beta$-cells can maintain normal plasma glucose concentrations by compensatory hyperinsulinemia. Overt type 2 diabetes occurs only when $\beta$-cells numbers fall or become dysfunctional and can no longer maintain the hyperinsulinemia required to maintain normoglycemia. ${ }^{33}$ Early in the natural history of type 2 diabetes, compensatory hyperinsulinemia is successful in overcoming the insulin resistance and maintaining euglycemia. Failure of incretin effect leads to relative insulinopenia and hyperglycemia. GLP-1 secretion is reduced in non-diabetic obese subjects, suggesting that 
incretin secretion may be altered early in the natural history of diabesity. ${ }^{34}$

A number of investigators have documented a reduced incretin effect in type 2 diabetes. ${ }^{35,36}$ This finding implies that signals from gut-derived factors are attenuated because of decreased concentrations of incretin hormones or resistance to their effects. Studies on GIP secretion in type 2 diabetes report decreased, normal, and increased responses ${ }^{37}$ Earlier studies on secretion of GLP-1 in type 2 diabetes suggested that circulating concentrations are raised, but recent studies employing better control of metabolic factors and more specific analytical assays indicate a near absence. ${ }^{38}$

\section{Autonomic function and incretin response}

Many workers have explored the correlation between the autonomic nervous system and the incretin response. Henderson et al found a significant reduction by atropine on insulin release after oral, but not after intravenous, glucose administration. ${ }^{39}$ Flaten et al showed that isoproterenol increased GIP and insulin responses after an oral glucose load in healthy humans and this effect was counteracted by propranolol. ${ }^{40}$ In a canine study the incretin effect was significantly attenuated by administration of propanolol, but not by atropine or phentolamine. ${ }^{41}$ In another animal study, Ikeda et al found that propranolol inhibited GIP- and GLP-1-induced insulin release. ${ }^{42}$

Therefore there are several indications in favor of an involvement of a sympathetic/parasympathetic mechanism in the regulation of the incretin effect. It stands to reason, therefore, that autonomic dysfunction may affect the response to incretin therapy in patients with diabetes.

To confirm this hypothesis, a study was conducted on 20 type 2 diabetes patients with and without autonomic neuropathy (AN), to assess the effect of AN on incretin response, compared with 10 healthy control subjects. ${ }^{43}$ Total insulin and C-peptide responses during oral glucose tolerance test (OGTT) were significantly higher than those after IV glucose infusion in the group of normal subjects, but not in the groups of diabetic patients. After the oral glucose load, GIP levels were significantly increased in normal subjects and patients without AN, whereas GLP-1 levels increased only in normal subjects. Based on insulin responses, the incretin effect [Incretin effect $=$ difference between total integrated amount of insulin or C-peptide during OGTT (A) and intravenous glucose infusion $(B)=(A-B) / A-100]$ was $56.5 \%$ in normal subjects, $37.3 \%$ in diabetic subjects without $\mathrm{AN}$, and $10.9 \%$ in patients with AN. The differences between the groups were significant only between normal subjects and patients with $\mathrm{AN}(P<0.01)$.

Based on C-peptide responses, the incretin effect was $39.9 \%, 22.1 \%$, and $5.9 \%$, respectively, with significant differences between controls and both patient without AN $(P<0.05)$ and with AN $(P<0.01)$.

In contrast to IV glucose infusion, oral glucose administration decreases hepatic insulin clearance, whereas method of glucose administration does not affect C-peptide clearance. As insulin and C-peptide are secreted into the portal circulation in equimolar amounts, ${ }^{44}$ this difference in clearance should be responsible for the higher incretin effect calculated from insulin responses in this study.

GIP responses to a mixed meal have been noted to be significantly reduced in type 2 diabetic patients in comparison with healthy subjects. If the group of diabetic patients was further divided into subjects with and without AN, the GIP responses were significantly decreased only in those with AN. In diabetics without AN, GIP responses were similar to those of controls. The authors suggested that this finding could be related to the loss of autonomic control of gastric emptying or the GIP secretion on autonomic modulation. ${ }^{45}$ These studies indicate a possible effect of autonomic neuropathy on the incretin effect in type 2 diabetes, through modulation of GIP secretion and hepatic insulin extraction, as suggested in other studies. ${ }^{4,46,47}$ It appears that GIP is more affected by autonomic neuropathy than GLP-1. Hence autonomic neuropathy could be an important factor affecting the response rate to gliptins. It may not be relevant for GLP-1 analogs.

\section{Metabolic function and incretin response}

GLP-1 control glucose homeostasis through well-defined actions on the islet $\beta$-cell via stimulation of insulin secretion and preservation and expansion of $\beta$-cell mass. Hansotia et $\mathrm{al}^{48}$ examined the importance of endogenous incretin receptors for control of glucose homeostasis through analysis of Glp1r-/-, Gipr-/-, and double incretin receptor knockout (DIRKO) mice fed a high-fat diet. DIRKO mice failed to upregulate levels of plasma insulin, pancreatic insulin mRNA transcripts, and insulin content following several months of high-fat feeding. Both single incretin receptor knockout and DIRKO mice exhibited resistance to diet-induced obesity, preservation of insulin sensitivity, and increased energy expenditure associated with increased locomotor activity. Moreover, plasma levels of plasminogen activator inhibitor-1 and resistin failed to increase significantly in DIRKO mice after high-fat feeding, and the GIP receptor 
agonist (D-Ala2) GIP, but not the GLP-1 receptor agonist exendin-4, increased the levels of plasma resistin in studies of both acute and chronic administration. These findings extend our understanding of how endogenous incretin circuits regulate glucose homeostasis independent of the $\beta$-cell via control of adipokine secretion and energy expenditure.

Resting energy expenditure is directly proportional to fasting plasma GLP-1 concentration. ${ }^{49}$ In humans, Donahoo and co-workers also found an increase in energy expenditure induced by peripheral GLP-1 administration in healthy young men. ${ }^{50}$ They used the hyperglycemic clamping technique, which resulted in high levels of plasma insulin. The effects on energy expenditure were abolished when the GLP-1 induced insulin secretion was blocked by somatostatin. On closer inspection it seems that energy expenditure might be more dependent on plasma insulin levels than on the GLP-1 administration itself. Another study, conducted on Pima Indians, confirmed that basal and 24-hour energy expenditure adjusted for body composition, spontaneous physical activity (SPA), sex, and age are higher in individuals with type 2 diabetes compared with non-diabetic control subjects and may be even more pronounced in Caucasians.

Resting energy expenditure can be predicted by fat-free mass, and sympathetic nervous activity. ${ }^{50}$ GLP-1 can activate the sympathoadrenal system at both central and peripheral levels, ${ }^{50-52}$ and increase energy expenditure (EE). ${ }^{32}$ The thermogenic effect, of GLP-1 is accompanied by tachycardia, which points to an activation of the sympathoadrenal system. ${ }^{14}$ A positive association between GLP-1 and sympathetic activity has also been demonstrated in the postprandial state. ${ }^{52}$

Fasting plasma GLP-1 concentrations are negatively associated with respiratory quotient, and serum pancreatic polypeptide, ${ }^{49}$ which is considered a valid surrogate marker of parasympathetic drive to the gastrointestinal system. ${ }^{53}$

Together, these data may indicate that GLP-1 analog administration will be of relatively more benefit in persons with parasympathetic overdue, who are not able to perform lipolysis and fatty acid oxidation as efficiently as persons with sympathetic activation.

\section{Biochemical parameters and incretin response}

Researchers have analyzed insulin secretion after oral glucose load in first-degree relatives of type 2 diabetes patients, and in women with a history of gestational diabetes mellitus, and found normal GIP and GLP-1.54,55 It has therefore been concluded that the reduction of GLP-1 concentration in patients with type 2 diabetes is a consequence of the disease, rather than an antecedent, as both these groups of patients often go on to develop diabetes.

In a study comparing 17 patients with type 2 diabetes, 17 with impaired glucose tolerance, and 14 normal subjects, plasma GIP and GLP-1 were noted to increase in all groups after both oral glucose and mixed-meal ingestion. ${ }^{56}$ There was a strong negative association between fasting glucagon levels and GLP-1 levels, as assessed by incremental area under curve (AUC) after oral glucose and meal ingestion. A positive correlation was seen with GLP-1 levels and integrated decremental glucagon levels after a glucose or meal load.

A positive correlation was seen with GLP-1 and free fatty acid (FFA) levels, while integrated decremental FFA levels were inversely related to GLP-1. ${ }^{56}$ Similar associations were noted for GIP.

GLP-1 increased with advancing age, and decreased with higher body mass index. These associations were stronger after glucose intake than after mixed meal. GLP-1 concentrations were noted to be higher in females than in males. All these associations were statistically significant. ${ }^{56}$

These findings suggest that GLP-1 analog therapy should be more effective in obese patients, in the elderly, in patients with lower fasting plasma FFA, and higher fasting glucagon concentrations. The drugs should theoretically be more effective in patients with high AUC FFA and low AUC glucagon after glucose or test meal load.

The same study ${ }^{56}$ found no association between GLP-1 or GIP levels and measures of glucose control (fasting and 120 minutes glucose, $\mathrm{HbA}_{1 \mathrm{c}}$ ), markers of insulin secretion (HOMA $\beta$-cell function), and markers of insulin sensitivity (HOMA insulin resistance). This means that GLP-1 analogs can be prescribed to patients irrespective of prior glycemic control or insulin resistance levels. This observation is proven by the beneficial results noted with the LEAD studies on liraglutide. ${ }^{12}$

Various studies done in different sets of patients report variable results. The above-mentioned study, which was carried out in patients with good control $\left(\mathrm{HbA}_{1 \mathrm{c}} 6.8 \% \pm 0.9 \%\right)$ and short duration of diabetes ( $3.2 \pm 2.8$ years $)$, showed definite results for predictors of GLP-1 secretion. On the other hand, studies done in patients with longer duration of action and higher $\mathrm{HbA}_{1 \mathrm{c}}$ levels did not reveal such results. ${ }^{57}$

Researchers studied 50 type 2 diabetes patients with or without autonomic/sensory neuropathy, and were unable to find any correlation between age, presence of neuropathy, obesity, $\beta$-cell function, and insulin sensitivity, and response to GLP-1 infusion. ${ }^{57}$ 
However, $\mathrm{HbA}_{1 \mathrm{c}}$, fasting plasma glucose, fasting nonesterified fatty acid (NEFA) concentration, AUC NEFA, and DPP-4 activity was correlated negatively, and significantly, with glucose disappearance constant $(\mathrm{Kg})$.

The parameters that demonstrated a positive correlation with $\mathrm{Kg}$ were fasting insulin, peak insulin, delta insulin, and $\log$ HOMA 2. Multiple regression showed that the only predictors of nadir plasma glucose were baseline fasting glucose and $\mathrm{Kg}$, with high baseline glucose leading to high nadir glucose. Multiple regression analysis also revealed that only high fasting plasma glucose was a significant correlate of $\mathrm{Kg}$.

This implies that GLP-1 analogs will be more effective in less severe diabetes, and should preferentially be prescribed to patents with better $\beta$-cell function.

However, the tropic effects of GLP- 1 on the $\beta$-cell indicate that all diabetic patients will benefit from GLP-1 analog therapy. ${ }^{58,59}$ The study confirmed that $100 \%$ of patients given GLP-1 infusion responded to it, and the majority (78\%) reached stable normoglycemia. Whether this finding can be extrapolated to GLP-1 analog therapy needs more study.

As GLP-1 has glucagonostatic action, ${ }^{60,61}$ the negative relationship between fasting glucagon and GLP-1 is understandable. The positive correlation between postprandial glucagon and GLP-1 may be explained by GLP-2, which is a glucagontropic hormone secreted in equimolar amounts as GLP-1 from the L-cells. ${ }^{62}$ It is possible that GLP-2, which is degraded much more slowly than GLP-1, increases glucagon secretion, and thus leads to higher glucagon levels after meal or glucose intake.

The effect of glucagon on GLP-1, and vice versa also, needs to be examined in detail. In healthy subjects, glucagon inhibits GLP-1 secretion, which rises after calorie intake, in parallel with a postprandial decline in $\alpha$-cell secretion. In patients with diabetes, nutrient intake does not suppress glucagon, and the lack of change in $\alpha$-cell function prevents the rise (change) in GLP-1 secretion. ${ }^{62}$

\section{Genetic markers and incretin response}

Recently, polymorphisms in the transcription factor 7-like 2 gene (TCF7L2) have been associated with type 2 diabetes. ${ }^{63}$ These polymorphisms have been shown to increase the risk of developing the disease in multiple ethnic groups, by $\sim 1.46$-fold ${ }^{64}$ by reducing glucose-induced insulin secretion. Eight subjects with risk-conferring TCF7L2 genotypes (TT or TC at rs7903146) and 10 matched subjects with wild-type genotype (CC) were studied to assess the exact mechanism by which this increase in risk occurred. They underwent 5-hour oral OGTT, isoglycemic intravenous glucose infusion, and graded glucose infusion. The incretin effect was assessed from ratios of the insulin secretory rates during oral and isoglycemic glucose infusions. ${ }^{65}$

$\beta$-cell response to oral glucose was $50 \%$ lower ( $47 \pm 4$ vs $\left.95 \pm 15 \times 10^{9} \mathrm{~min}^{-1} ; P=0.01\right)$ in the group of subjects with risk-conferring TCF7L2 genotypes compared with control subjects. The incretin effect was also reduced by $30 \%$ (32 \pm 4 vs $46 \pm 4 \% ; P=0.02)$ in the at-risk group. The lower incretin effect occurred despite similar GIP and GLP-1 responses to oral glucose. The insulin secretory rate response to intravenous glucose over a physiologic glucose concentration range (5-9 mmol/L) was similar between groups. ${ }^{65}$

The TCF7L2 variant rs7903146 appears to increase risk of type 2 diabetes, at least in part, by modifying the effect of incretins on insulin secretion. This is not due to reduced secretion of GLP-1 and GIP but rather to the effect of TCF7L2 on the sensitivity of the $\beta$-cell to incretins. This may explain why different patients respond differently to incretin therapy. The molecular mechanisms responsible for the reduced $\beta$-cell response to GLP-1 and GIP as a function of TCF7L2 genotype have not been defined and warrant further investigation. TCF7L2 is a Wnt signalingassociated transcription factor that plays an important role in the synthesis of GLP-1 in intestinal L-cells. ${ }^{66}$ It was thus expected that genetic variation in TCF7L2 would lead to reduced secretion of GLP-1 and GIP. Clearly this is not the case. In addition, the diabetes-associated variants in TCF7L2 have been shown to have increased, rather than decreased, islet levels of TCF7L2 mRNA. ${ }^{67}$ Interestingly, Shu et al recently reported that increased levels of TCF7L2 mRNA in $\beta$-cells are actually associated with decreased TCF7L2 proteins, indicating altered regulation at a posttranscriptional level. ${ }^{68}$ The reduction in TCF7L2 protein was found to correlate with downregulation of GIP and GLP receptors, resulting in decreased Akt phosphorylation and Akt-mediated Foxo-1 phosphorylation, and, therefore, impaired $\beta$-cell function.

\section{Conclusion}

In summary several factors determine the response rate to incretin therapy. Minimal clinical data are available to make any conclusion. Key factors appear to be duration of diabetes, obesity, presence of autonomic neuropathy, resting energy expenditure, plasma glucagon level, and plasma free fatty acid levels. More clinical evidence is required to identify the factors affecting response rate to insulin therapy. 


\section{Disclosure}

The authors disclose no conflicts of interest.

\section{References}

1. Creutzfeldt W. The incretin concept today. Diabetologia. 1979;16: 75-85.

2. Ebrick H, Stimmler L, Hlad CJ, Arai Y. Plasma insulin response to oral and intravenous glucose administration. J Clin Endocrinol Metab. 1964;24:1076-1082.

3. Tillil H, Shapiro ET, Miller MA, et al. Dose-dependent effects of oral and intravenous glucose on insulin secretion and clearance in normal humans. Am J Physiol. 1988;254:E349-E357.

4. Nauk MA, Homberger E, Siegel EG, et al. Incretin effects of increasing glucose loads in man calculated from venous insulin and C-peptide responses. J Clin Endocrinol Metab. 1986;63:492-498.

5. Tseng CC, Kieffer TJ, Jarboe LA, et al. Postprandial stimulation of insulin release by glucose-dependent insulinotropic polypeptide receptor antagonist in the rat. J Clin Invest. 1996;98:2440-2245.

6. Kolligs F, Fehmann HC, Goke R, Goke B. Reduction of the incretin effect in rats by the glucagons-like peptide 1 receptor antagonist exendin (9-39)amide. Diabetes. 1995;44:16-19.

7. Scrocchi LA, Brown TJ, MaClusky N, et al. Glucose intolerance but normal satiety in mice with a null mutation in the glucagon-like peptide 1 receptor gene. Nat Med. 1996;2:1254-1258.

8. Kreymann B, Williams G, Ghatei MA, Bloom SR. Glucagon-like peptide-1. 7-36: a physiological incretin in man. Lancet. 1987;2:1300-1304.

9. Orksov C, Wettergren A, Hoist JJ. Secretion of the incretin hormones glucagon-like peptide-1 and gastric inhibitory polypeptide correlates with insulin secretion in normal man throughout the day. Scand J Gastroenterol. 1996;31:665-670.

10. Vilsboll T, Krarup T, Madsbad S, Holst JJ. Both GLP-1 and GIP are insulinotropic at basal and postprandial glucose levels and contribute nearly equally to the incretin effect of a meal in healthy subjects. Regul Pept. 2003;114:115-121.

11. Drucker DJ. Biological actions and therapeutic potential of the glucagon-like peptides. Gastroenterology. 2002;122:531-544.

12. Kalra S, Kalra B, Sharma A. Liraglutide - a novel GLP-1 analogue. Recent Patents on Endocrine, Metabolic and Immune Drug Discovery. 2009;3(3):200-204.

13. Moretto TJ, Milton DR, Ridge TD, MacConell LA, Okersen T, Wolka AM, et al. Efficacy and tolerability of exenatide monotherapy over 24 weeks in antidiabetic drug-naive patients with type 2 diabetes: a randomized, double-blind, placebo-controlled, parallel-group study. Clin Ther. 2008;30:1448-1460.

14. Kim T, Taylor K, Wilhelm K, et al. Exenatide once weekly treatment elicits sustained glycemic control and weight loss over 2 years. Abstract 159-OR. Diabetes. 2009;58(Suppl 1):A42.

15. Raz I, Hanefeld M, Xu L, Caria C, Williams Herman D, Khatami H. Efficacy and safety of the dipeptidyl peptidase-4 inhibitor sitagliptin as monotherapy in patients with type 2 diabetes. Diabetes Care. 2006;49: 2564-2571.

16. Buse JB, Rosenstock J, Sesti G, et al; for LEAD-6 Study Group. Liraglutide once a day versus exenatide twice a day for type 2 diabetes: a 26-week randomised, parallel-group, multinational, open-label trial (LEAD-6). Lancet. 2009;374:39-47.

17. Pratley RE, Nauck M, Bailey T, Montanya E, Cuddihy R, Filetty S, et al; for the 1860 LIRA DPP 4 Study Group. Liraglutide versus sitagliptin for patients with type 2 diabetes who did not have adequate glycaemic control with metformin: a 26-week, randomised, parallel-group, open-label trial. Lancet. 2010;375:1447-1456.

18. Garber A, Henry R, Ratner R, Garcia-Hernandez PA, Rodriguez-Pattzi H, Olvera-Alvarez I, et al. Liraglutide versus glimepiride monotherapy for type 2 diabetes (LEAD-3 Mono): a randomised, 52-week, phase III, double-blind, parallel-treatment trial. Lancet. 2009;373:473-481.
19. Mojsov S, Weir GC, Habener JF. Insulinotropin: glucagon-like peptide I (7-37) co-encoded in the glucagon gene is a potent stimulator of insulin release in the perfused rat pancreas. Clin Invest. 1987;79:616-619.

20. Flamez D, Gilon P, Moens K, et al. Altered cAMP and $\mathrm{Ca} 2+$ signaling in mouse pancreatic islets with glucagon-like peptide-1 receptor null phenotype. Diabetes. 1999;48:1979-1986.

21. Dyachok O, Isakov Y, Sågetorp J, Tengholm A. Oscillations of cyclic AMP in hormone-stimulated insulin-secreting $\beta$-cells. Nature. 2006;439:349-352.

22. Serre V, Dolci W, Schaerer E, et al. Exendin-(9-39) is an inverse agonist of the murine glucagon-like peptide-1 receptor: implications for basal intracellular cyclic adenosine 3',5'-monophosphate levels and beta-cell glucose competence. Endocrinology. 1998;139:4448-4454.

23. Buteau J, Roduit R, Susini S, Prentki M. Glucagon-like peptide-1 promotes DNA synthesis, activates phosphatidylinositol 3-kinase and increases transcription factor pancreatic and duodenal homeobox gene 1 (PDX-1) DNA binding activity in beta (INS-1)-cells. Diabetologia. 1999;42:856-864.

24. Kang G, Chepurny OG, Holz GG. cAMP-regulated guanine nucleotide exchange factor II (Epac2) mediates $\mathrm{Ca}^{2+}$-induced $\mathrm{Ca}^{2+}$ release in INS-1 pancreatic beta-cells. J Physiol. 2001;536:375-385.

25. Wang Y, Egan JM, Raygada M, Nadiv O, Roth J, Montrose-Rafizadeh C. Glucagon-like peptide-1 affects gene transcription and messenger ribonucleic acid stability of components of the insulin secretory system in RIN 1046-38 cells. Endocrinology. 1995;136:4910-4917.

26. Fehmann HC, Habener JF. Insulinotropic hormone glucagon-like peptide-I (7-37) stimulation of proinsulin gene expression and proinsulin biosynthesis in insulinoma beta TC-1 cells. Endocrinology. 1992;130: 159-166.

27. Skoglund G, Hussain MA, Holz GG. Glucagon-like peptide 1 stimulates insulin gene promoter activity by protein kinase A-independent activation of the rat insulin I gene cAMP response element. Diabetes. 2000;49:1156-1164.

28. Kemp DM, Habener JF. Insulinotropic hormone glucagon-like peptide 1 (GLP-1) activation of insulin gene promoter inhibited by $\mathrm{p} 38$ mitogenactivated protein kinase. Endocrinology. 2001;142:1179-1187.

29. Pugazhenthi U, Velmurugan K, Tran A, Mahaffey G, Pugazhenthi S. Anti-inflammatory action of exendin-4 in human islets is enhanced by phosphodiesterase inhibitors: potential therapeutic benefits in diabetic patients. Diabetologia. 2010;53:2357-2368.

30. Holz GG 4th, Kühtreiber WM, Habener JF. Pancreatic beta-cells are rendered glucose-competent by the insulinotropic hormone glucagonlike peptide-1 (7-37). Nature. 1993;361:362-365.

31. Dachicourt N, Serradas P, Bailbé D, Kergoat M, Doaré L, Portha B. Glucagon-like peptide-1 (7-36)-amide confers glucose sensitivity to previously glucose-incompetent beta-cells in diabetic rats: in vivo and in vitro studies. J Endocrinol. 1997;155:369-376.

32. Stumvoll M, Fritsche A, Stefan N, Hardt E, Häring H. Evidence against a rate-limiting role of proinsulin processing for maximal insulin secretion in subjects with impaired glucose tolerance and beta-cell dysfunction. J Clin Endocrinol Metab. 2001;86:1235-1239.

33. DeFronzo RA. Pharmacologic therapy for type 2 diabetes mellitus. Ann Intern Med. 2000;133:73-74.

34. Ranganath LR, Beety JM, Morgan LM, et al. Attenuated GLP-1 secretion in obesity: cause or consequence. Gut. 1996;38:916-919.

35. Nauck M, Stockmann F, Ebert R, et al. Reduced incretin effect in type 2 (non-insulindependent) diabetes. Diabetologia. 1986;29:46-52.

36. Nauck MA, Baller B, Meier JJ. Gastric inhibitory polypeptide and glucagon-like peptide-1 in the pathogenesis of type 2 diabetes. Diabetes. 2004;53:S190-S196.

37. Fehmann HC, Goke R, Goke B. Cell and molecular biology of the incretin hormones glucagon-like peptide-1 and glucose-dependent insulin releasing polypeptide. Endocr Rev. 1995;16:390-410.

38. Mannucci E, Ognibene A, Cremasco F, et al. Glucagon-like peptide (GLP)-1 and leptin concentrations in obese patients with type 2 diabetes mellitus. Diabetes Med. 2000;17:713-719. 
39. Henderson JR, Jefferys DB, Jones RH, Stanley D. The effect of atropine in the insulin release caused by oral and intravenous glucose in human subjects. Acta Endocrinol (Copenh). 1976;83:772-780.

40. Flaten O, Sand T, Myren J. Beta-adrenergic stimulation and blockade of the release of gastric inhibitory polypeptide and insulin in man. Scand J Gastroenterol. 1982;17:283-288.

41. Chap Z, Okuda Y, Pena J, Field JB. Beta-adrenergic stimulation contributes to incretin effect in conscious dogs. Am J Physiol. 1991;261: E58-E65.

42. Ikeda T, Ochi H, Ohtani I, et al. Possible role of the adrenergic mechanism in gastric inhibitory polypeptide- and glucagon-like-peptide-1 (7-36) amide-induced insulin release in the rat. Metabolism. 1993;42: 209-213.

43. Kazakos KA, Sarafidis PA, Yavos JG. The impact of diabetic autonomic neuropathy on the incretin effect. Med Sci Monit. 2008:14:CR 213-220.23.

44. Horwitz DL, Starr JI, Mako ME, et al. Proinsulin, insulin and C-Peptide concentrations in human portal and peripheral blood. $J$ Clin Invest. 1975;55:1278-1283.

45. Levitt NS, Vinik AI, Child PT. Glucose dependent maturity-onset diabetes: effects of autonomic neuropathy. J Clin Endocrinol Metab. 1980;51:254-258.

46. Wettergren A, Wojdemann M, Meisner S, Stadil F, Holst JJ. The inhibitory effect of glucagons-like peptide-1(GLP-1)7-36 amide on gastric acid secretion in humans depends on an intact vagal innervation. Gut. 1997;40:597-601.

47. Wettergen A, Wojdermann M, Holst JJ. Glucagon-like peptide-1 inhibits gastropancreatic function by inhibiting central parasympathetic outflow. Am J Physiol. 1998:275:G984-G992.

48. Hansotia T, Maida A, Flock G, et al. Extrapancreatic incretin receptors modulate glucose homeostasis, body weight, and energy expenditure. J Clin Invest. 2007;117:143-152.

49. Pannacciulli N, Bunt JC, Koska J, Bogardus C, Krakoff J. Higher fasting plasma concentrations of glucagon like peptide 1 are associated with higher resting energy expenditure and fat oxidation rates in humans. Am J Clin Nutr. 2006;84:556-560.

50. Donahoo WT, Levine JA, Melanson EL. Variability in energy expenditure and its components. Curr Opin Clin Nutr Metab Care. 2004;7:599-605

51. Yamamoto H, Lee CE, Marcus JN, Williams TD, Overten JM, Lopez ME, et al. Glucagon like peptide 1 receptor stimulation increases bloodpressure and heart rate and activates autonomic regulatory neurons. J Clin Invest. 2002;110:43-52.

52. Pannaaci N, de Courteen B, Brookshire TL, Del Parigi A, Holst JJ, Tataranni PA. GLP-1 response to a mixed meal is associated with SNS activity in humans: a microneurography analysis. Obes Res. 2005;13: A107(abstr).

53. Schwartz TW, Holst JJ, Fahrenkrug J, et al. Vagal, cholinergic regulation of pancreatic polypeptide secretion. J Clin Invest. 1978;61:781-789.

54. Meier JJ, Gallwitz B, Askenas M, et al. Secretion of incretin hormones and the insulinotropic effect of gastric inhibitory polypeptide (GIP) in women with a history of gestational diabetes. Diabetologia. 2005;48:1872-1881.
55. Nauk MA, EI Ouaghlidi A, Gabrys B, Hucking K, Holst JJ, Deacon CF, et al.Secretion of incretin hormones (GIP and GLP-1) and incretin effect after oral glucose in first-degree relatives of patients with type 2 diabetes. Regul Peptides. 2004;122:209-217.

56. Vollmer K, Holst JJ, Baller B, Ellrichmann M, Nauck MA, Schmidt WE, et al. Predictors of incretin concentrations in subjects with normal impaired, and diabetic glucose tolerance. Diabetes. 2008;57: 678-687.

57. Toft-Nelsen MB, Madsbad S, Holst JJ. Determinants of effectiveness of glucagon like peptide-1 in type 2 diabetes. J Clin Endocrinol Metab. 2001;86:3853-3860.

58. Xu G, Stoffers DA, Habener JF, Bonner-Weir S. Exendine-4 stimulates both beta-cell replication and neogenesis, resulting in increased betacell mass and improved glucose tolerance in diabetic rats. Diabetes. 1999;48:2270-2276.

59. Zhou J, Wang X, Pineyro MA, Egan JM. Glucagon-like peptide 1 and exendin-4 convert pancreatic AR42j cells into glucagon- and insulinproducing cells. Diabetes. 1999;48:2358-2366.

60. Orskov C, Hoist JJ, Neisen OV. Effect of truncated glucagon-like peptide-1 [proglucagon (78-107) amide] on endocrine secretion from pig pancreas, antrum, and noantral stomach. Endocrinology. 1988;123:2009-2013.

61. Nauk MA, Kleine N, Orskov C, Hoist JJ, Willms B, Creutzfeldt W. Normalization of fasting hyperglycemia by exogenous glucagon-like peptide 2 stimulates glucagon secretion enhances lipid absorption, and inhibits gastric acid secretion in humans. Diabetologia. 1993;36: 741-744.

62. Meier JJ, Nauk MA, Pott A, Hienze K, Goetze O, Bulut K, et al Glucagon-like peptide 2 stimulates glucagon secretion, enhances lipid absorption, and inhibits gastric acid secretion in humans. Gastroenterology. 2006;130:44-54.

63. Grant SF, Thorleifsson G, Reynisdottir I, Benediktsson R, Manolescu A, Sainz J, et al. Variant of transcription factor 7-like 2 (TCF7L2) gene confers risk of type 2 diabetes. Nat Genet. 2006;38:320-323.

64. Cauchi S, El Achhab Y, Choquet H, Dina C, Krempler F, Weitgasser R, et al. TCF7 L2 is reproducibly associated with type 2 diabetes in various ethnic groups: a global meta-analysis. J Mol Med. 2007;85:777-782.

65. Villareal DT, Robertson H, Bell GI, Patterson DW, Tran H, Wise B, et al. TCF7L2 variant rs7903146 affects the risk of type 2 diabetes by modulating incretin action. Diabetes. 2010;59:479-485.

66. Jin T, Liu L. The Wnt signaling pathway effector TCF7L2 and type 2 diabetes mellitus. Mol Endocrinol. 2008;22:2383-2392.

67. Lyssenko V, Lupi R, Marchetti P, et al. Mechanisms by which common variants in the TCF7L2 gene increase risk of type 2 diabetes. $J$ Clin Invest. 2007;117:2155-2163.

68. Shu L, Matveyenko AV, Kerr-Conte J, Cho JH, McIntosh CH, Maedler K. Decreased TCF7L2 protein levels in type 2 diabetes mellitus correlate with downregulation of GIP- and GLP-1 receptors and impaired beta-cell function. Hum Mol Genet. 2009;18:2388-2399.

Research and Reports in Endocrine Disorders

\section{Publish your work in this journal}

Research and Reports in Endocrine Disorders is an international, peerreviewed, open access journal publishing original research, reports, reviews and commentaries on all areas of endocrinology, endocrine disorders and therapeutic interventions. The manuscript management system is completely online and includes a very quick and fair

to read real quotes from published authors.

\section{Dovepress}

Submit your manuscript here: http://www.dovepress.com/research-and-reports-in-endocrine-disorders-journal 